\title{
A modular simulation study to improve patient flow to inpatient units in the emergency department
}

\author{
Shaghayegh Norouzzadeh ${ }^{1}$, J oseph Garber ${ }^{2}$, Melonie Longacre ${ }^{2}$, Salaahuddin Akbar ${ }^{1}$, Nancy Riebling ${ }^{1}$, \\ Robin Clark ${ }^{3}$ \\ 1. Center for Learning and Innovation, North Shore-LIJ Health System, Lake Success, NY, United States. 2. Syosset
} Hospital, North Shore-LIJ Health System, Syosset, NY, United States. 3. The QMT Group, Oak Ridge, TN, United States.

Correspondence: Shaghayegh Norouzzadeh. Address: Improvement Sciences, Center for Learning and Innovation, North Shore - LIJ Health System, 1979 Marcus Avenue, Suite 101, Lake Success, NY, United States. E-mail:

snorouzzad@nshs.edu

Received: August 28, 2014

Accepted: October 18, 2014

Online Published: November 13, 2014

DOI : $10.5430 /$ jha.v3n6p205

URL: http://dx.doi.org/10.5430/jha.v3n6p205

\section{Abstract}

In this study, a modular discrete event simulation (computer modeling) has been presented to support process improvements in a hospital's emergency department (ED) to streamline admitted patient flow to inpatient units. Because the ED in this study has less than 10 beds, unnecessary occupation of beds affects the patient wait time dramatically. Additionally, ED overcrowding diminishes the quality of care, increases costs, and decreases employee and patient satisfaction. The modular simulation model evaluated the effectiveness of several recommended workflow improvements, resulting from comprehensive statistical analysis, based on their impact on cycle time and time traps in the process. The results suggested that, to ensure better efficiency and optimal cycle time, all of the suggested workflow improvements should be implemented simultaneously. The model also suggested that achieving customer satisfaction is possible $96.26 \%$ of the time with the current resource allocations in the ED.

\section{Key words}

Discrete event simulation, Emergency department flow, Process improvement

\section{I ntroduction}

Emergency department (ED) crowding is a nationwide problem that results in delayed treatments, long patient wait times, overburdened staff, unnecessarily high costs, and low patient throughput ${ }^{[1,2]}$. Crowding can lead to other problems, such as medical errors and complications ${ }^{[3]}$. Overcrowding also diminishes the ability of the ED to provide immediate access and stabilization to those patients who have an urgent medical condition ${ }^{[4,5]}$. Excessive patient overload also leads to decreased physician productivity ${ }^{[6-8]}$. Long ED holds across hospitals in the United States are proven to be decidedly correlated to higher patient length of stay (LOS) on inpatient care units ${ }^{[1,9,10]}$. Inability to transfer admitted patients to inpatient beds has been reported to be the most serious cause of ED overcrowding ${ }^{[2,11]}$. Improving ED efficiency to transfer patients to proper inpatient care units and reducing crowding is of significant importance. Due to criticality of the ED in a health system, it is not always feasible to test and pilot proposed improvements in such an environment. To achieve the desired outcomes, comprehensive and accurate analysis as well as modeling of ED workflow to evaluate the effectiveness of the improvements are critical requirements. 


\subsection{Problem background}

Computer simulations have become an increasing trend to use as effective decision support systems to make more reliable decisions in healthcare and improve operations ${ }^{[12]}$. A simulation model can represent the patient flow and care delivery processes, emulate the process and its dynamics under certain random distributions, and provide predictions for performance measurement. Such a tool can help healthcare management to evaluate the efficiency of the current practices, carry out "what if" analyses to predict the impact of staffing, resources, and operational changes, to determine the optimal system configurations, and investigate the relationships or trade-offs among system variables.

\subsection{Goals, objectives, and contributions of this study}

Although several strategies have been attempted with varying degrees of success, the problem still exists in hospitals across the United States. More than two thirds of US EDs are affected by overcrowding ${ }^{[13]}$. Generic simulation models would not only be able to accurately capture the ED patient flow dynamics and identify improvement strategies, but also provide quantitative assessment of gains from improvement measures before their actual implementation. Due to the high complexity of an ED system, a valid generic mathematical model for such a system would be extremely difficult. However, Discrete Event Simulation (DES), a branch of computer simulation science, is an effective tool for studying such a complex system ${ }^{[14,15]}$.

In this study, a generic parametric DES simulation has been developed to investigate the causes of the overcrowding and strategies to resolve them. The objective is to utilize simulated results to explore the effectiveness and quantify the potential gains from various improvement alternatives. The proposed method enables the hospital to quantify the effect of system redesign prior to implementation and to examine how the strategies can be best applied, which ultimately decreases implementation costs and disruptions. The contribution of this study to show how a structured analysis of patient flow can replace piloting changes in the ED where interruptions and changes can be very critical and costly for the patients and the department. A second major contribution is to demonstrate how simulation modeling and the quantitative analysis that it provides can assist in convincing key stakeholders to implement improvements.

The remainder of this paper is structured as follows. The background of ED simulation models is presented in Section 2 . The proposed methodology is discussed in Section 3. Analysis and comparison of experimental results of the model is conversed in Section 4. Finally, conclusions and future work are presented in Section 5.

\section{Healthcare simulation in literature}

Healthcare simulation is an active area of research and practice, with the ED being one of the most popular areas for modeling ${ }^{[16]}$. Popularity of ED simulations is due to the fact that EDs are relatively self-contained with easily observable processes over relatively short periods of time. Improvements in performance are easier to demonstrate and link to specific actions, which may not be true elsewhere in healthcare ${ }^{[17]}$. Application of DES to identify and analyze the problems and recommending the best optimal solutions in the literature can be categorized as depicted in Figure 1.

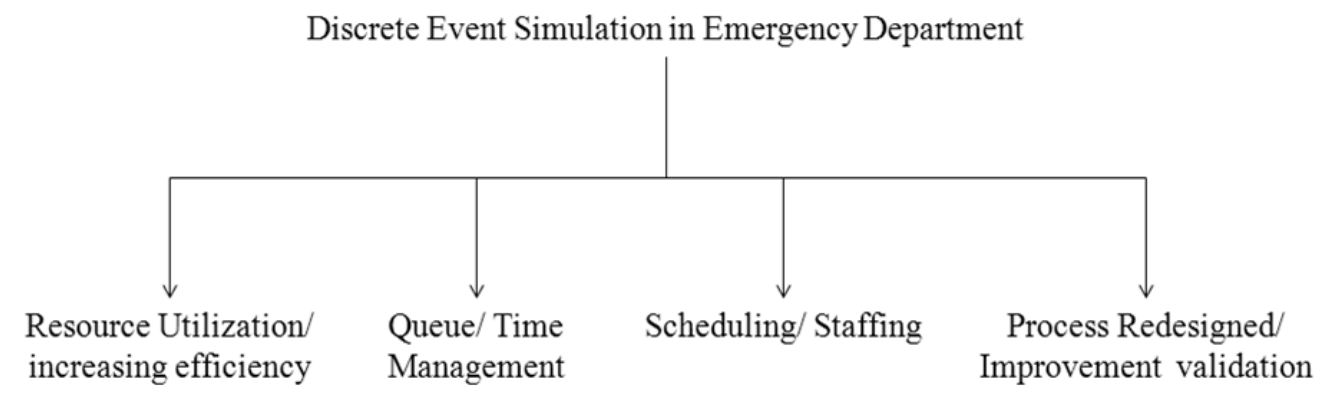

Figure 1. Categories of discrete event simulation application in the ED 
There are examples in the literature for each category; however, the focus of this study is on the last category, process redesign ${ }^{[18-21]}$. Oftentimes, DES has been applied to validate the improvements in a process redesign, since changes with high level of uncertainty in the ED can result in serious situations. A computer simulation study was presented to improve the quality of care at a community hospital $\mathrm{ED}^{[1]}$. The quality of care has been evaluated in terms of length of stay and the percentage of patients leaving without being seen. Sensitivity analyses have been carried out to improve the flow of nursing team policies by trying two different scenarios. Scenario one was two nurses for six rooms versus one nurse per three rooms. The second scenario was adding more nurses and scanners. In addition, a DES simulation model has been applied to support the implementation of a split-flow process ${ }^{[22]}$. The split-flow concept is an emerging approach to manage ED processes by splitting patient flow according to patient acuity of care. This simulation model was created to establish the validity of improvements in the ED department. Findings supported that the implementation of the split-flow significantly reduced patient LOS. While numerous ED simulation studies appear in literature, few recommendations resulting from the DES modeling have actually been implemented ${ }^{[23,24]}$.

One of the major issues with the implementation is that often operational changes are made that require the system to be redesigned, which is challenging in healthcare setting. Studies have been designed to explore the reasons why healthcare fails to adopt simulation and modeling techniques that can help to highlight ways towards greater adoption ${ }^{[25]}$. To further explore these reasons, a system of classification of healthcare topics were proposed, and usefulness of simulation modeling techniques were examined ${ }^{[26]}$. The correlation between the simulation approach and the healthcare application was then investigated. Finally, to get a better understanding of the usage of DES in healthcare systems, a survey was conducted to assess how many healthcare institutions have used DES as a decision making tool ${ }^{[27]}$. The results indicated that costs, lack of awareness, lack of frontline staff and management engagements, and lack of skills within the internal staff are the main reasons against a wide utilization of DES. To improve the compliance in implementation, an agenda for further inquiry was proposed in terms of importance of stakeholders, healthcare system culture, availability of data, and management expectations in simulation studies success likelihood ${ }^{[28]}$. The study was designed in a systematic way to answer questions leading towards greater adoption of the modeling. Recent studies focused on barriers to implement and uptake the simulation in healthcare by describing the nature of the healthcare problems and team approaches, which can explain why implementation cannot be used to measure the success.

Since crowding is a very common problem in EDs, strategies proposed to overcome ED overcrowding are varied. Several examples of ED DES models are available in the extant literature. In this study, the generic interdisciplinary process was modeled, including steps that are shared between ED, inpatient unit, primary care physician, and patient transportation. The proposed model then has been used to test scenarios resulting from extensive qualitative and quantitative analysis. A group of content experts provided the qualitative analysis and statistical analysis of data provided the quantitative information so that both optimum solutions and the engagement of the key stakeholders can be ensured.

\section{Proposed methodology}

ED overcrowding, the primary focus of this study, can result either from shortage or inappropriate scheduling of resources, such as medical professionals directly involved in care delivery, or it can be due to inefficiencies in the process of providing care. The purpose of this DES is to develop an ED model for admitted patients and evaluate improvement scenarios to decrease inefficiencies in the providing care process.

\subsection{Assumptions}

The hospital in this study is a 72-bed community hospital located on Long Island, NY, with an ED with less than 10 beds. The ED at this hospital faces 17,500 patient visits per year, about $17 \%$ of whom are admitted to an inpatient unit. The focus of this simulation study is to improve the patient flow from decision to admit time in the ED to physical presence of the patient in an inpatient unit. The throughput is defined as cycling of patients or their information through physical resources and process steps after the admission decision is made in the ED to occupy a bed in an inpatient unit over a period of time. 
As the baseline, the average throughput time was about 194 minutes with standard deviation equal to 78 minutes. However, pre-studies within the health system indicated that throughput time greater that 180 minutes can reduce patient satisfaction. The simulation model was carried out to evaluate optimal configuration of workflows for a list of improvement strategies. Since the admitted patient status is critical, it was assumed that none of the patients leave the system in the middle of the process and that they stay in the system.

\subsection{Simulation scope, setting, and constraints}

In this study, the process starts when the ED physician assessment of the patient, based on patient's laboratory and radiology results, indicates necessity of admission and the process ends when the patient is in the bed on the decided inpatient care unit. The interactions between the physicians, nurses (RNs), nurse managers, nurse assistants, clerks, and nurse supervisors are the focus of this study. However, since the first assessment of the ED physician was based on the test results from laboratory and radiology, their turnaround time was out of the scope in this process. The ED staff work in two shifts every day. The day shift is from 7:00 am to 7:00 pm and the night shift is from 7:00 pm to 7:00 am during weekdays and weekends. On the other hand, the inpatient units are running on three shifts per day. The day shift is from 7:00 am to 3:00 pm, the afternoon shift is from 3:00 pm to $11: 00 \mathrm{pm}$, and the night shift is from 11:00 pm to 7:00 am during weekdays and weekends. Since the patient in the ED has already occupied a bed, ED beds were not a constraint in the simulation. The data implied that unavailability of inpatient unit beds results in huge delays in patient transfer time, which only occurred for about $19 \%$ of the cases. However, there was still a huge opportunity to improve the delays in the process for the other $80 \%$ of cases where bed availability in the inpatient unit was not a constraint. The DES was addressing the turnaround time for cases where a bed was available on the inpatient unit for baseline and alternative scenarios. Finally, adding resources and staffing were not a feasible alternative for the ED under study and was not provided in this study. Therefore, the simulation focus was on streamlining the process to send a patient to an inpatient unit when bed availability was not an issue.

\subsection{Process flow diagram}

The patient flow was mapped based on ED and inpatient unit staff, including the physicians, RNs, nurse managers, nurse supervisors, nurse assistants, and clerks input through a process mapping session and validated by a walkthrough in the hospital, as illustrated in Figure 2. This step focused on obtaining a thorough understanding of detailed operational logic and procedure performed in the ED using a process flow diagram. Specifically, the following process steps are typical for an admitted patient in the ED:

1) ED physician uses the laboratory and radiology results if needed to assess the patient in the ED and makes admission decision;

2) If the patient needs to be admitted, the ED physician will call the primary care physician (PCP) to consult the case and determine the admitting care unit;

3) Two parallel sub-process will start from this point:

i. Bed Assignment

- ED Physician asks the ED RN to complete the admitting form

- $\quad$ ED RN calls the inpatient unit to get an assigned bed

- Unit RN calls ED with bed assignment

ii. Admitting Order Completion

- The PCP has the option to write the online order or visiting patient in the ED before writing the order

4) When the orders are completed and the bed is assigned, the ED RN calls the RN on the inpatient unit for the RN-RN report; 
5) The patient is transferred to the inpatient unit after the report is done.

Based on the defined steps in the process, a discrete event simulation model using ExtenSim 8.01 was developed to emulate the patient flow in the ED to the inpatient care units.

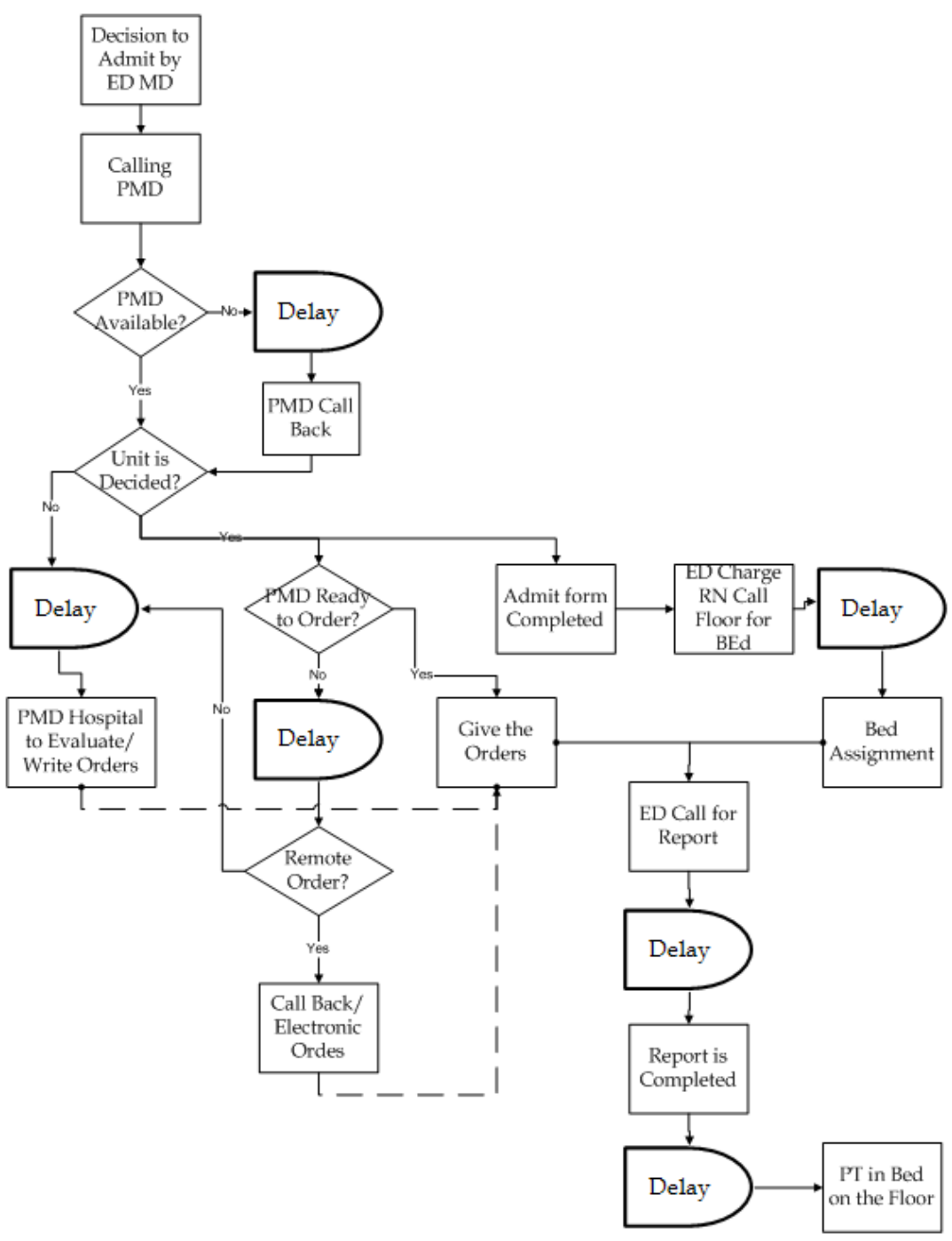

Figure 2. Current admission process map

\subsection{Reducing system complexity through classification of activities}

All the activities identified in the previous section were classified into one of the two categories: waiting (for example waiting for bed or admission orders) or care delivery time. This organization of the steps helped to prioritize the activities that need to be improved or eliminated. Each of the waiting times and care steps occurred in the following five subsystems:

- Admission decision

- $\quad$ Bed assignment

- Admission order completion

- Hand-off report completion

- Patient transportation to inpatient unit 


\subsection{Admission decision to patient in bed probability distributions}

A manual data collection tool was designed to collect the data in the ED and on the inpatient care units for each step of the process. Fitted distribution, based on the data analysis, was used to represent various care delivery processes. Creating variables, such as number of patients waiting to be transferred, change at discrete points of time.

The developed DES model had the ability to capture the process steps of a system as a network of interdependent and discrete events. The DES model enacted the events using the priority based rules from the routing policies that drive the actual ED operations. The primary statistical analysis showed no significant statistical difference in patient transfer time for admission decisions in day and night shifts or during the weekdays and weekends. The number of admissions by hour of the day for 316 data points followed Weibull distribution with Shape parameter equal to 3.30 and Scale parameter equal to 16.42 as depicted in Figure 3. Therefore, with the use of such data, a unique admission decision distribution was generated and used as the input in the simulation model.

Figure 3. Admission decision distribution

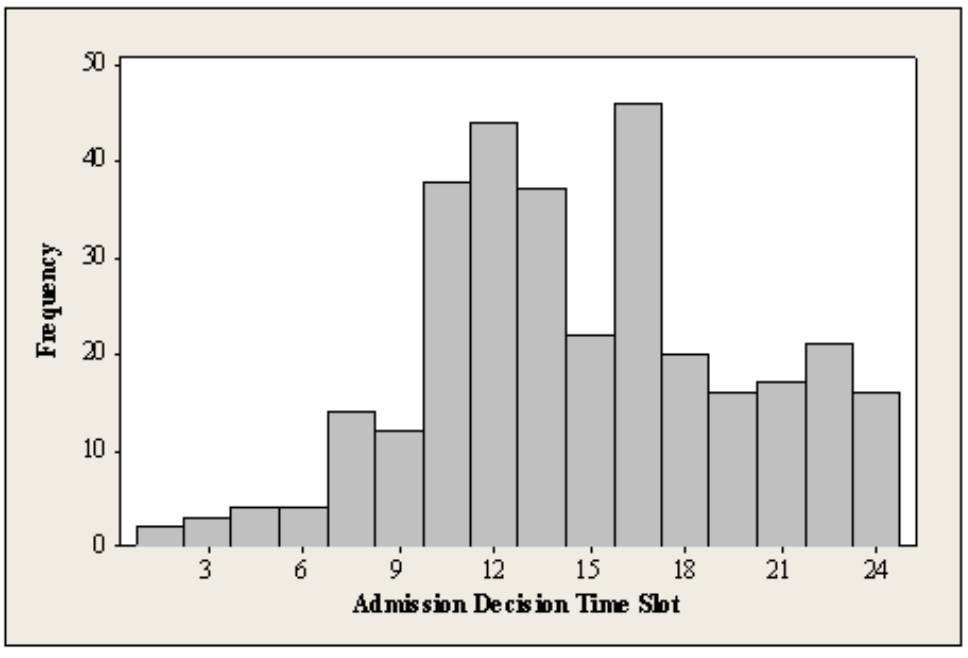

\subsection{Routing policies}

To address the resource constraints in the model, the collected data was used to calculate and assign the route probabilities, i.e. percentage of the patients who receive electronic orders versus onsite orders or percentage of times the RN-RN report is completed by one call versus multiple calls as illustrated in Table 1.

Table 1. Default simulation settings in simulation control panel

\begin{tabular}{ll}
\hline Items & \\
\hline Primary Care Physician Make Admission Decision & $86 \%$ on Phone $-14 \%$ on Site \\
Primary Care Physician Complete Admission Orders & $32 \%$ Remote $-68 \%$ On Site \\
Bed Assignment Number of Calls & $11 \%$ One Call $-89 \%$ Multiple Calls \\
Report Completion Number of Calls & $3 \%$ One Call $-97 \%$ Multiple Calls \\
\hline
\end{tabular}

\subsection{Design of simulation}

ExtendSim v8.1 was used to develop the model. The simulation model followed the flow as depicted in the process map in Figure 4. The design of the simulation had five phases. In the first phase, the historical data and current process map was used to build the model. In phase two through four, the alternative scenarios for order completion, bed assignment, and report completion then were added as an option to the model. Finally, the model had the capability to run all the process changes simultaneously and evaluate the results. 


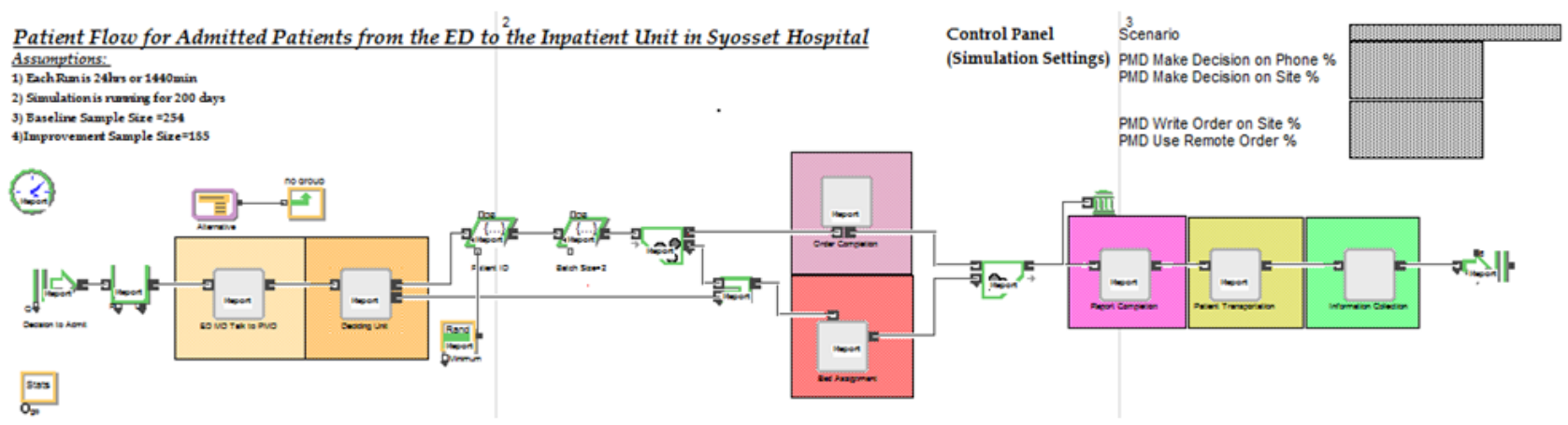

Figure 4. Simulation model in ExtendSim v8.1

\subsection{Model verification and validation}

Throughout the design and development of the simulation model, several techniques were employed to ensure the reliability of DES recommendations and verify and validate the model including:

1) The model was verified by ensuring that entities are flowing through the model correctly.

2) The model was validated by:

- Validating the model logic and assumptions by field experts.

- Applying quantitative and statistical tests to ensure that the outputs of the simulation match the outputs in reality as shown in Table 2 . All the $P$-values are greater than 0.05 ; therefore, with $95 \%$ confidence level, there was no significant difference between the actual results and the simulation results. Also, graphical methods for the overall throughput are shown in Figure 5. As shown in Table 2, variability and central tendency of patient turnaround time for each subsystem obtained from the model is compared to actual data.

- Also, the model was run under extreme conditions and results were analyzed, concluding that the model performed as expected under all conditions.

Figure 5. Graphical output of the simulation and actual data

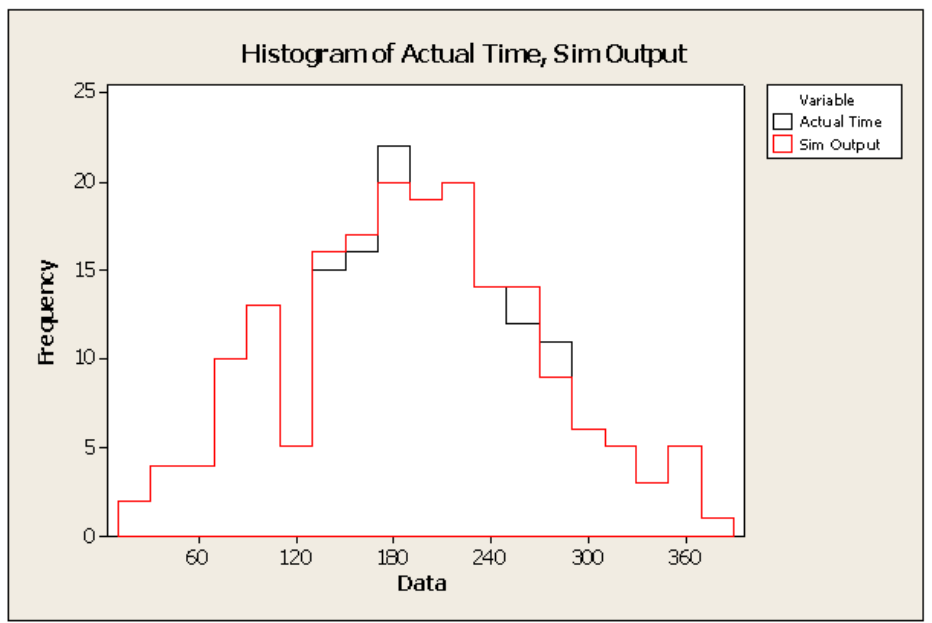

Once the DES model is built, it can be applied to analytically study and evaluate the impact of changes to inputs on the output measures of performance ${ }^{[15]}$. It is possible to measure the impact of improvement alternatives with the help of parametric models developed from simulation results that quantify the potential gains from each improvement alternative. Based on the results, the most appropriate recommendations can be determined. Finally, implementation of the recommendations is an effective final validation of the model contributions. To evaluate the simulation model, a follow-up study to compare the outcomes before and after the model recommendations was implemented in the ED. 
Table 2. Comparison between actual data and simulation data

\begin{tabular}{llllll}
\hline Activity & Sim Average & Actual Average & Sim SD & Actual SD & P-value \\
\hline PMD Call Back for Admission & 17.98 & 15.23 & 3.56 & 7.23 & .70 \\
Admit From Completion & 14.96 & 11.40 & 2.45 & 3.40 & .38 \\
PMD Evaluate on Site Before Admission & 14.08 & 21.36 & 23.21 & 15.36 & .07 \\
Remote Order Completion & 35.21 & 46.88 & 3.11 & 12.65 & .28 \\
Onsite Order Completion & 86.45 & 86.96 & 20.33 & 17.96 & .98 \\
ED RN Call for Bed After Admission Decision & 20.86 & 22.88 & 3.65 & 3.40 & .70 \\
Bed Assignment if Bed Available & 42.24 & 54.75 & 20.15 & 19.65 & .67 \\
ED RN Call for Report & 10.78 & 11.81 & 5.23 & 4.08 & .88 \\
Report Completion & 74.87 & 75.50 & 16.41 & 18.88 & .37 \\
PT Transportation & 16.72 & 15.86 & 1.25 & 2.23 & .71 \\
Overall Patient Throughput & 192.84 & 193.99 & 78.78 & 78.28 & .89 \\
\hline
\end{tabular}

\section{Discussion and limitations}

\subsection{Results and metrics}

The data driven simulation tool developed and tested several scenarios arising from operational concerns and results of detailed and extensive statistical inferring. As a benchmark, a baseline simulation was developed to emulate the current situation. The baseline was then compared to the scenarios where one of the improvement strategies was implemented. In particular, the improvement strategies are discussed in the following sections:

\subsubsection{Providing a central depository for bed assignment}

In the recommended scenario, the nursing supervisor was receiving the bed request from ED and assigned bed by considering patient conditions and bed availability in each inpatient unit.

\subsubsection{Push/ pull RN report at bedside process}

In the proposed scenario, if the inpatient unit RN doesn't reply or arrive at the bedside for the report within 30 minutes after the first call, which happens $20 \%$ of the time based on the data, the ED nurse calls the inpatient unit and pushed to transfer the patient to floor for the bedside report. However, around $80 \%$ of the time the inpatient unit RN pulled the patient from the ED by arriving at the bed side or calling the ED to schedule an appropriate report time.

\subsubsection{Encouraging remote orders or hospitalist brief admission orders}

Due to the unavailability of the primary care physicians and the underutilization of the hospitalist in the hospital, if the orders were not written by the primary care physician either electronically or onsite within 90 minutes, 34\% of time, then the hospitalist would write a brief order for the admission.

The results of implementing each improvement separately and all simultaneously are provided in Table 3 and show the effectiveness of strategies.

As illustrated in Table 3, brief admission order may not improve the average time because there is still a 90-minute time window for the PCP to write the orders, but it reduced the variation in the process. However, central bed depository and push/pull bedside report process could significantly improve the average time by removing the non-value added steps from the process. 
Table 3. Results of implementing alternative improvements

\begin{tabular}{llllc}
\hline Improvement & Mean Throughput Time & SD & $\begin{array}{l}\text { Mean Percent } \\
\text { Improvement }\end{array}$ & $\begin{array}{l}\text { SD Percent } \\
\text { Improvement }\end{array}$ \\
\hline $\begin{array}{l}\text { Providing a central depository for bed } \\
\text { assignment }\end{array}$ & 168.75 & 78.40 & $13.01 \%$ & $0.01 \%$ \\
$\begin{array}{l}\text { Push/Pull RN Report at Bedside Process } \\
\text { Encouraging Remote Orders or }\end{array}$ & 165.49 & 71.77 & $14.69 \%$ & $8.31 \%$ \\
$\begin{array}{l}\text { Hospitalist Brief Admission Orders } \\
\text { All }\end{array}$ & 187.49 & 15.3 & $3.35 \%$ & $80.45 \%$ \\
\hline
\end{tabular}

\subsection{Limitations of the simulation model}

Although the results of the model proved the effectiveness of the improvement strategies, changing the culture in a system and getting the buy-in from the stakeholders is certainly a challenging task. To address the role and criticality of the stakeholders in practical value of simulation, the following eight factors were taken into consideration in this study ${ }^{[29]}$ :

- $\quad$ Form a steering group

- Involve the group in proposing alternative scenarios for simulation

- Having a champion in the organization

- $\quad$ Conduct a feasibility study considering rules and policies within the organization

- Develop data collection plans considering data quality

- $\quad$ Try to simplify the model, but still answering the stakeholders questions

- $\quad$ Try to make the model as generic and parametric as possible

- $\quad$ Involve end-users at all stages for validating the model

- $\quad$ Promote the results

One of the most critical success factors was having a "champion" within the healthcare organization, someone who appreciates the value of simulation modeling and was able to persuade their colleagues that the modeling is worthwhile. Building such relationships can take time, but pays high rewards in the long run ${ }^{[30]}$. Several of these stakeholders' engagement factors helped in fostering the trustful relationship and maintaining a non-biased stance. A parametric model empowers the stakeholders in a small community hospital to test various improvement scenarios in a safe, but reliable setting at minimum cost. At current state the proposed model has limited generalizability to the organizational complexities in a tertiary ED. However, challenges such as increasing patient volume or type, routing optimization problem due to longer distance between departments, and necessity of a more robust communication process can be captured and analyzed by additional modules in the proposed DES model to represent a tertiary facility.

\section{Conclusions}

In this study, a DES model has been presented to support process improvements in a hospital ED to streamline admitted patient flow to inpatient units in a community hospital. Since the ED under study had a very limited number of beds $(<10)$, unnecessary occupation of each of the beds affects the patient waiting time and quality of patient care dramatically. As a result, ED overcrowding diminishes care delivery qualities, increases costs, while decreases staff and patient satisfaction. The modular simulation model evaluated the efficiency of a list of recommended workflow improvements, resulting from comprehensive statistical analysis, regarding their cycle time and the time traps in the process and compares it to the current workflow. The results indicated that providing a central depository for bed assignment and Push/Pull RN Report at 
Bedside Process could improve the average throughput time by almost 13\%; however, Encouraging Remote Orders or Hospitalist Brief Orders affected the variation but not the average time by almost $80 \%$. Overall, implementation of all improvement strategies resulted in $41 \%$ improvement in the average throughput time and $63 \%$ reduction in variation. As a conclusion, the model suggested that meeting customer satisfaction is possible $96.26 \%$ of the time by having the throughput less than 180 minutes with the proposes setting and current resource allocation in the ED.

\section{References}

[1] Zeng Z, Ma X, Hu Y, Li J, Bryant D. A Simulation Study to Improve quality of Care in the emergency department of a Community hospital. Journal of Emergency Nurses Association. 2012; 38(4): 322-328. PMid: 21963136. http://dx.doi.org/10.1016/j.jen.2011.03.005

[2] Solberg LI, Asplin BR, Weinick RM, Magid DJ. Emergency Department Crowding: Consensus Development of Potential Measures. Ann Emerg Med. 2003; 42: 824-33. http://dx.doi.org/10.1016/S0196-0644(03)00816-3

[3] Bertsimas D, Bjarnadottir MV, Kane MA, Kryder JC, Pandey R, Vempala S, et al. Algorithmic prediction of health-care costs. Operational Research. 2008; 56(6): 1382-1392. http://dx.doi.org/10.1287/opre.1080.0619

[4] Derlet RW, Richards JR. Overcrowding in the Nation's Emergency Departments: Complex Causes and Disturbing Effects. Ann Emerg Med. 2000; 35: 63-8. http://dx.doi.org/10.1016/S0196-0644(00)70105-3

[5] Bittencourt RJ, Hortale VA. A systematic review intervention to solve overcrowding in hospital emergency services. Cad. Saude Publica. 2009; 25(7): 1439-1454. PMid: 19578565. http://dx.doi.org/10.1590/S0102-311X2009000700002

[6] Case RB, Fite DL, Davis SM, Hoxhaj S, Jaquis VP, Seay T, et al. Emergency department crowding information. American College of Emergency Physicians. 2012. Available from: http://www.acep.org/ WorkArea/DownloadAsset.aspx?id=8872

[7] Rondeau KV, Francescutti LH, Zanardelli J. Emergency Department Overcrowding: the Impact of Resource Scarcity on Physician Job Satisfaction. Journal of Healthcare Management. 2005; 50(5): 257-340.

[8] Jarousse LA. ED throughput: a Key to Patient Safety. Hospital Health Networks. 2011; 85(8): 33-40. PMid: 21928575.

[9] Jensen J. Going with the flow. Tracking System Helps Midwest Hospital Streamline Patient Flow and Lower Emergency Room Divert Rate. Health Management. 2003; 24(12): 43-45.

[10] Falvo T, L Grove L, Stachura R, Zirkin W. The financial impact of ambulance diversions and patient elopements. Acad. Emerg. Med. 2007; 14(1): 58-62. PMid: 17200514. http://dx.doi.org/10.1111/j.1553-2712.2007.tb00372.x

[11] Howell E, Bessman ES, Rubin HR. Hospitalists and an Innovative Emergency Department Admission Process. Gen Intern Med. 2004; 19: 266-8. http://dx.doi.org/10.1111/j.1525-1497.2004.30431.x

[12] Jacobson SH, Hall SN, Swisher JR. Discrete Event Simulation of Health Care Systems. Hall RW, ed. Patient Flow: Reducing Delay in Healthcare Delivery. New York: Springer. 2006; 211-52.

[13] Knapp J, Bojko T, Dolan M, Frush K, Furnival R, Isaacman D, et al. Overcrowding Crisis in Our Nation's Emergency Departments: Is Our Safety Net Unraveling? Pediatrics. 2004; 114 (3): 878-888. PMid: 15342870. http://dx.doi.org/10.1542/peds.2004-1287

[14] Fishman G S. Discrete Event Simulation: Modeling, Programming, and Analysis. Springer series in operations research. New York: Springer. 2001. http://dx.doi.org/10.1007/978-1-4757-3552-9

[15] Law AM. Simulation Modeling and Analysis. McGraw-Hill Series in Industrial Engineering and Management Science. New York: McGraw-Hill. 2007.

[16] Gunal M, Pidd M. Discrete Event Simulation for Performance Modeling in Health Care: a Review of the Literature. Journal of Simulation. 2010; 4(1): 42-51. http://dx.doi.org/10.1057/jos.2009.25

[17] Paul SA, Reddy MC, DeFlitch CJ. A Systematic Review of Simulation Studies Investigating Emergency Department Overcrowding. Simulation. 2010; 86(8-9): 559-571.

[18] Gul M., Guneri AF. A Computer Simulation Model to Reduce Patient Length of Stay and to Improve Resource Utilization Rate in an Emergency Department Services System. International Journal of Industrial Engineering. 2012; 19(5): 221-231.

[19] Ceglowski L, Churilov L, Wasserthiel J. Combining Data Mining and Discrete Event Simulation for a Value-added View of a Hospital Emergency Department. The Journal of Operational research Society. 2007; 58(2): 246-254.

[20] Paul J., Lin L. Models for Improveing Patient Throughput and Waiting at Hospital Emergency Departments. The Journal of Emergency Medicine. 2012; 43(6): 1119-1126. PMid: 22902245. http://dx.doi.org/10.1016/j.jemermed.2012.01.063

[21] Hamorock E. Discrete Event Simulation for Healthcare Organizations, Discrete Event Simulation for Healthcare Organizations. Journal of Health Management. 2013; 58(2): 112-124. 
[22] Konard R, DeSotto K, Grocela A, McAuley P, Wang J, Lyons J, et al. Modeling the Impact of Changing Patient Flow Processes in an Emergency Department: Insights from a Computer Simulation Study. Operational Research for Healthcare. 2013 ; 2: 66-74.

[23] Eldabi T. Implementation Issues of Modeling Healthcare Problems: Misconceptions and Lessons. Proceedings of the 2009 winter Simulation Conference, edited by MD Rossetti, RR. Hill, B. Johansson, A. Dunkin and R G. Ingalls. 2009; 1831-1839. http://dx.doi.org/10.1109/WSC.2009.5429192

[24] Sobolev BG, Sanchez V, Vasilakis C. Systematic Review of the Use of Computer Simulation Modeling of Patient Flow in Surgical Care. Journal of Med. Sys. 2011; 35(1): 1-16. PMid: 20703590. http://dx.doi.org/10.1007/s10916-009-9336-z

[25] Fackler J., Hankin J. Why Healthcare Professionals are Slow to Adopt Modeling and Simulation. Proceedings of the 2012 winter Simulation Conference, edited by C. Laroque, J. Himmelspach, R. Pasupathy, O. Rose, and A.M. Uhrmacher. 2012; $1092-1097$. http://dx.doi.org/10.1109/WSC.2012.6465330

[26] Mielczarek B., Uzialko-Mydlikowska J. Application of Computer Simulation Modeling in Healthcare Sector: A Survey. Simulation. 2010; 88(2): 197-216. http://dx.doi.org/10.1177/0037549710387802

[27] Kirchhof P., Meseth N. A Survey on the Use of Simulation in German Healthcare. Proceedings of the 2012 winter Simulation Conference, edited by C. Laroque, J. Himmelspach, R. Pasupathy, O. Rose, and A.M. Uhrmacher. 2012; 1082-1091. http://dx.doi.org/10.1109/WSC.2012.6465026

[28] Terry Y, Jahangirian M, Lilford R. Three Critical Challenges for Modeling and Simulation in Healthcare. Proceedings of the 2009 winter Simulation Conference, edited by MD. Rossetti, RR. Hill, B. Johansson, A. Dunkin and R. G. Ingalls. 2009; $1823-1830$.

[29] Harper PR, MA Pitt. On the Challenges of Healthcare Modeling and a Proposed Project Life-cycle for Successful Implementation Journal of the Operational Research Society. 2004; 55: 657-661.

[30] Brailsford S, Bolt T, Connell C, Klein JH, Patel B. Stakeholder Engagement in Healthcare Simulation. In Proceedings of the 2009 winter Simulation Conference, edited by MD. Rossetti, RR. Hill, B. Johansson, A. Dunkin and RG. Ingalls. 2009; 1840-1849. http://dx.doi.org/10.1109/WSC.2009.5429190 